Bl ocking of two-el ectron reducti on of non- charged speci es in the absence of supporting el ectrol yte at nanoel ectrodes

\begin{tabular}{|l|l|}
\hline 著者 & $\begin{array}{l}\text { Zhang Chaof u, Aoki Koi chi Jer emi ah, Chen } \\
\text { Ji ngyuan, N shi um Toy ohi ko }\end{array}$ \\
\hline $\begin{array}{l}\text { j our nal or } \\
\text { publ i cat i on ti tl e }\end{array}$ & Journal of El ect r oanal yt i cal Chemi st ry \\
\hline vol ume & 708 \\
\hline page range & $101-107$ \\
\hline year & $2013-05$ \\
\hline URL & ht t p: //hdl . handl e. net /10098/8100 \\
\hline
\end{tabular}




\title{
Blocking of two-electron reduction of non-charged species in the absence of supporting electrolyte at nanoelectrodes
}

\author{
Chaofu Zhang, Koichi Jeremiah Aoki ${ }^{*}$, Jingyuan Chen, Toyohiko Nishiumi \\ Department of Applied Physics, University of Fukui \\ Bunkyo 3-9-1, Fukui, Japan, 910-0015
}

\begin{abstract}
1,4-Benzoquinone (BQ) and tetracyanoquinodimethane (TCNQ), which are reduced consecutively to mono-anions and dianions under conventionally voltammetric conditions, cannot be reduced up to the dianions without supporting electrolyte in acetonitrile solution. Effects of the $I R$-drop and the electrostatic force in low concentrations of supporting electrolyte are examined by use of the first reduction waves. They apply to the analysis of the second waves. Voltammograms without supporting electrolyte at microelectrodes with the diameters less than $0.4 \mu \mathrm{m}$ do not include noticeably $I R$-drop. The large overpotential for the anions cannot be explained in terms of the electric migration which has been estimated from solutions of the Nernst-Planck equation and the Laplace equation. With an increase in the conductivity of the solution by addition of electrolyte, the second reduction wave appears, involving the potential shift. The electrolyte does not influence the first reduction waves but varies the second one. The salt effect specific to the second wave is ascribed to non-stoichiometric association of the redox anion with the salt cation.
\end{abstract}

key words: microelectrode voltammetry; mass transport by diffusion and electric migration; without supporting electrolyte; Nernst-Planck equation;

\footnotetext{
* Corresponding author (K. J. Aoki), e-mail: kaoki@u-fukui.ac.jp, phone (+81) 90 8095-1906
} 


\section{Introduction}

Interpretation of Faradaic currents at low concentration of electrolyte is a classical subject [1-3]. It has revived since currents of 1 nano-ampere order at microelectrodes have provided negligible amount of $I R$-drop of solution resistance without deliberately adding supporting electrolyte [4-11]. Theoretical work on voltammetry in low concentration of supporting electrolyte has been developed for various combinations of charge numbers of redox species and supporting electrolyte [12-21]. The experimental results and the theory on the electric migration have been reviewed in the context of microelectrode techniques $[22,23]$. The subject of low concentrations of electrolyte can result conceptually not only in the $I R$-drop by solution resistance but also in the mass transport problem complicated by the electric field $[12,15]$. The former is relevant to the potential distribution in a cell which varies mainly with geometry of a cell and electrodes, specifically with a distance between a working electrode and a counter electrode. The solution resistance can be expressed by the Laplace equation or accurately the Poisson equation [24]. In contrast, the latter is relevant to the mass transport in diffusion layer, which is represented by the Nernst-Planck equation [25] composed of fluxes by diffusion and the electric field.

The lower the concentration of supporting electrolyte, the more electrostatically a redox ion interacts with the electrolyte. The interaction lets the redox ion generate complex-like species with salts, exemplified by labile species of lead, cadmium and mercury ions [26,27]. This effect cannot be elucidated by the Nernst-Planck equation, because it belongs to molecularly scaled behavior rather than the macroscopically continuum model by the Nernst-Planck equation. Steady-state currents [28] and cyclic voltammograms [29] including the complexation have been numerically obtained on the assumption of complexation with definite stoichiometry. The numerical results have been applied to thiocyanate complexes of mercury in the absence of supporting electrolyte [30]. The complex-like species has been generated unintentionally with inert 
salts present as impurities or with dissociation of the solvent, as for instance $\mathrm{OH}^{-}$in aqueous solution [26]. The complexation may be readily formed in dianions or dications rather monomeric ions.

The prototypical species that forms dianions is tetracyanoquinodimethane (TCNQ), which exhibits the two-step consecutive reduction [10,11,31,32]. The second reduction wave was quite sensitive to electrolyte concentration [10,32]. The concentration-dependence has been ascribed to the homogeneous bimolecular reaction (comproportionation) of the neutral species with the dianion [33], as has often been considered for ion-exchange reactions [11,31,34-38]. It has been demonstrated, however, the comproportionation has any effect on the voltammograms only when there are difference in values of diffusion coefficients of the reactant, the anion radical and the cation $[10,31]$. Difference among them for TCNQ is not so large as to exhibit strong concentration-dependence of electrolyte [ 39 ]. If solution contains no ion, comproportionation may vary voltammograms complicatedly owing to difference in migration forces of the mono-anion and the dianion of TCNQ. Before considering this complication, it is necessary to consider in details the effects of the $I R$-drop, the electric field and the complexation on the voltammograms. The other explanation of the concentration-dependence is formation of the complex of the radical anion with cation of electrolyte, of which formation rate determines the current [32].

Voltammetry of non-charged species in the absence of electrolytes should show ohmic current-voltage lines because of the absence of any electric carrier in solution $[17,40]$. Voltammograms of non-charged species such as dioxygen [41], hydrogen gas [42], TCNQ [10,11], ferrocene [16,43,44], tetrathiafulvalene [10] and copper diethyldithiocarbamate [45], however, have shown clear enough shapes to identify the species or analyze the current-voltage curves. These voltammograms must be supported by ionic impurity included in solvents, redox species, water, or dissociated carbon dioxide. This report, first of all, deals with searching size of microelectrodes on which voltammograms of non-charged redox species can be obtained without potential shift in 
electrolyte-free solution. The size effect including both the $I R$-drop and the electrostatic force is examined by use of the first reduction waves of TCNQ and 1,4-benzoquinone (BQ). The result is applied to microelectrode voltammetry of TCNQ and BQ under the thus obtained conditions. The voltammograms are compared with the theoretical voltammograms including $I R$-drop and the electric field effect. The complexation with salt will be described to be responsible for appearance of the second reduction wave, depending on electrolyte concentrations.

\section{Experimental}

\subsection{Fabrication of microelectrodes}

Microdisk electrodes with various diameters were fabricated by the previous method $[46,47]$, which was composed of etching of a platinum wire, sealing it with a glass capillary by heat, dissolving the coating glass with hydrofluoric acid, and polishing the glass tip with a monitor of ac-impedance. The radii, $a$, of the electrodes were evaluated from the limiting currents, $I_{\mathrm{L}}$, in the acetonitrile solution including 0.1 $\mathrm{M}\left(=\mathrm{mol} \mathrm{dm}{ }^{-3}\right)$ tetrabutylammonium perchlorate $\left(\mathrm{TBAClO}_{4}\right)$ and $2 \mathrm{mM}\left(=c^{*}\right)$ ferrocene by use of $I_{\mathrm{L}}=4 F c^{*} \mathrm{Da}$, where the value of the diffusion coefficient, $D$, was $1.55 \times 10^{-5} \mathrm{~cm}^{2} \mathrm{~s}^{-1}[48]$.

\subsection{Chemicals}

All the chemicals were of analytical grade. Ferrocene was purified with sublimation to remove impurity which was included normally $10 \%$ [48]. TCNQ and BQ were used as received. Commercially available acetonitrile (99.9\%, Wako) was dried with molecular sieves of 3A type. The molecular sieves were washed with tetrahydrofuran and then dried in an oven at $300^{\circ} \mathrm{C}$ for $3 \mathrm{~h}$. Supporting electrolyte used was $\mathrm{TBAClO}_{4}$, which was dried in vacuum for 1 day. 


\subsection{Voltammetry}

Voltammetry was made in the two-electrode cell equipped with a working electrode and a counter electrode of a platinum coil. Reference electrodes were not used for voltammetry of TCNA or BQ without supporting electrolyte. They were used only for estimation of amounts of leakage ions from them. The potentiostat was HECS 972 (Huso, Kawasaki), controlled with a homemade software. The electrode was rinsed with solvent before being mounted in the cell. Voltammetry was carried out in deaerated solution in a Faraday cage. The conductometer was DS-71 (Horiba, Kyoto).

The $\mathrm{Ag} \mid \mathrm{AgCl}$ reference electrode was home-made, being very close in geometry to a commercial available one, for example, type RE-1B (BAS, Tokyo). It contained saturated concentration of $\mathrm{KCl}$. The silver oxide-coated silver wire was made by immersing a silver wire into the concentrated nitric acid for $5 \mathrm{~min}$. The silver chloride-coated silver wire was made by applying $1.2 \mathrm{~V}$ to a silver wire in $10 \mathrm{mV} \mathrm{HCl}$ solution for $30 \mathrm{~s}$. The reference electrode in salt-included acetonitrile was $\mathrm{Ag} \mid \mathrm{Ag}^{+}$, which contained $0.01 \mathrm{M} \mathrm{Ag}^{+}$and $0.1 \mathrm{M} \mathrm{TBAClO}_{4}$.

\section{Results and Discussion}

\subsection{Microelectrodes with negligible IR-drop}

A reference electrode is usually a main source of unwanted ions in an electrolytic cell [22]. In order to estimate ionic contamination from a reference electrode, we immersed the $\mathrm{Ag} \mid \mathrm{AgCl}$ (saturated $\mathrm{KCl}$ ) electrode into $70 \mathrm{~cm}^{3}$ deionized water, monitoring the conductivity of the solution during bubbling nitrogen gas. The conductivity rose up rapidly at first from $0.2 \mu \mathrm{S} \mathrm{cm}^{-1}$, and then increased linearly with the time, as is shown in Fig. 1 (open circles). This increase should be ascribed to leakage of $\mathrm{KCl}$ from the $\mathrm{Ag} \mid \mathrm{AgCl}$ electrode. A less contaminating electrode is a quasi-reference electrode composed of metal and sparing soluble salt or oxide. We obtained time-variations (in Fig. 1) of the pure water into which the silver oxide-coated 
silver wire and the silver chloride-coated silver wire were immersed. Although the conductivity by these electrodes was much less than that by the $\mathrm{Ag} \mid \mathrm{AgCl}$ electrode, it still increased with the time. The conductivity increased slightly even without inserting an electrode, as shown in Fig. 1 (filled circles).

Solution without including ion has theoretically such high resistance that current-voltage curves obey the Ohm's law [17,40]. Real solvents without deliberately adding electrolyte have, however, detectable conductance because of impurity, especially by dissociation of dissolved carbon dioxide or that of water in aprotic solvents, as is exemplified in Fig. 1 (filled circles). If current at a microelectrode is so small that the ohmic $I R$-drop may be negligible, voltammetry of non-charged redox species can be supported by small conductance of impurity. It is difficult to know a priory how small electrodes allow us to obtain acceptable voltammograms. We attempted to carry out voltammetry at various sized microelectrodes in dry and deaerated acetonitrile solution which included only equi-concentration of ferrocene and 1,4-benzoquinone (BQ). The voltammetry was made by the two electrode system in order to avoid contamination by a reference electrode. The counter electrode was a platinum wire. Since the cathodic charge by the reduction of BQ at the microelectrode can be compensated with the oxidation of ferrocene at the counter electrode, it is necessary not to take into account the reaction overpotential at the counter electrode. Examples of the voltammograms are shown in Fig. 2, where the current in the ordinate was divided by the diameters. This plot is convenient to display in one graph the voltammograms deviated by effects of the $I R$-drop from diffusion-controlled voltammograms at various sized electrode. The micrometer-sized electrode (d) showed ohmic current-voltage curves. The smaller the electrodes, the more clearly the sigmoidal form appeared.

It is necessary to examine whether the halfwave potential difference, $0.95 \mathrm{~V}$, between ferrocene and $\mathrm{BQ}$ in Fig. 2(a) is close to the thermodynamic potential difference. The thermodynamic potential difference can be realized approximately by 
the peak potential difference in conventional cyclic voltammograms. Figure 3 shows voltammograms of ferrocene, BQ and ferrocene at the $1.6 \mathrm{~mm}$ Pt disk electrode for $v=$ $0.1 \mathrm{~V} \mathrm{~s}^{-1}$ in the solution including electrolyte. BQ and TCNQ exhibit the two reduction peaks, as in the well-known behavior $[49,50]$. The difference in the peak potentials of BQ and ferrocene was $0.91 \mathrm{~V}$. This is close to the halfwave potential difference in Fig. 2(a). Therefore the $I R$-drop in Fig. 2(a) can be neglected.

We made a criterion of obtaining the maximum electrode diameter below which the $I R$-drop is negligible. We took the maximum current, $I_{\max }$, and the minimum one, $I_{\min }$, in the voltage domain from -1.2 to $0.6 \mathrm{~V}$. If the $I R$-drop is neglected, $I_{\max }$, and $I_{\min }$ should be equal to the oxidation and the reduction limiting currents of ferrocene and BQ, respectively. Voltammograms drawn out by the $I R$-drop ought to have $I_{\max }$ smaller than the limiting current. Then the amount, $\left(I_{\max }-I_{\min }\right) / 2 a$, may be smaller than the diffusion-controlled limiting current, $4([\mathrm{Fc}]]+[\mathrm{BQ}]) F D$, where $[\mathrm{Fc}]$ and $[\mathrm{BQ}]$ are bulk concentrations ferrocene and $\mathrm{BQ}$, respectively, $D$ is the common diffusion coefficient. Figure 4 shows the plot of $\left(I_{\max }-I_{\min }\right) / 2 a$ against $\log (2 a)$ in the solution of $2 \mathrm{mM}$ Ferrocene $+2 \mathrm{mM}$ BQ in acetonitrile when the potential window was $1.8 \mathrm{~V}(=\Delta V)$. Values of $\left(I_{\max }-I_{\min }\right) /(2 a \Delta V)$ were kept constant for $a<0.4 \mu \mathrm{m}$. The current at $a=0.4$ $\mu \mathrm{m}, 1.4 \mathrm{nA}$, corresponds $R=1.3 \mathrm{G} \Omega$ of the minimum solution resistance. This is equivalent to $\rho=2 \mathrm{k} \Omega \mathrm{m}$ of the resistivity which was obtained by use of $R=\rho / 4 \mathrm{a}$ [51]. It corresponds to the conductivity of $3 \mu \mathrm{M} \mathrm{KCl}$ solution.

\subsection{Voltammetry in low concentration of electrolyte}

Figure 5 shows voltammograms in the acetonitrile solution including ferrocene and BQ and that of ferrocene and TCNQ at the $2 a=40 \mathrm{~nm}$ electrode without adding electrolyte. Since the potential was measured vs. the counter electrode, the anodic wave of ferrocene including BQ was different from that including TCNQ. Wave (a) was re-plotted in Fig. 5 so that the former was overlapped with the latter. The halfwave 
potential differences between ferrocene and BQ and between ferrocene and TCNQ in Fig. 5 were almost the same as the peak potential differences of the conventional voltammograms in Fig, 3. Therefore the voltammograms in Fig. 5 has actually no participation in the $I R$-drop. The cathodic wave at $-3.0 \mathrm{~V}$ in Fig. 5 should be the reductive decomposition of acetonitrile, because it was observed even in the absence of BQ or TCNQ.

White et al observed the suppression of the second reduction wave of TCNQ in the absence of electrolyte $[10,11]$. It is predicted that deliberate addition of electrolyte may cause the second wave. Figure 6 shows dependence of voltammograms of ferrocene and TCNQ on concentrations of $\mathrm{TBAClO}_{4}$. The voltammogram at zero concentration of $\mathrm{TBAClO}_{4}$ showed almost the first reduction wave, leaving behind a small rise of the second wave near $-1.5 \mathrm{~V}$. With an increase in concentrations, the second reduction wave appeared and was shifted in the positive direction. The limiting current increased with the increase in the concentration. The further potential shift and the further increase in the current were not observed for the concentrations higher than $60 \mathrm{mM}$. The limiting current for $E<-0.8 \mathrm{~V}$ at concentrations over $60 \mathrm{mM}$ was twice as large as that of the first wave $[31,39]$. These variations indicate that the electrolyte should be responsible for the formation of TCNQ dianion. Voltammograms of BQ are shown in Fig. 7, exhibiting similar variation to Fig. 6 except for potentials. The suppression of the second waves for the low concentrations can be understood qualitatively by Born's energy, which mentions that formation energy of a dianion is four time larger than that of a mono-anion. Born's energy, however, cannot explain the variation of the limiting currents or the invariant potential of the first wave.

In order to discuss quantitatively the voltammograms, we obtained analytical expressions for the steady-state current-voltage curves of a two-step sequential reduction composed of $\mathrm{A}+\mathrm{e}^{-} \leftrightarrow \mathrm{A}^{-}$and $\mathrm{A}^{-}+\mathrm{e}^{-} \leftrightarrow \mathrm{A}^{2-}$ in high resistive solutions at a hemispherical electrode $a$ in radius on the assumption of a constant electric field. Since the derivation belongs to a mathematical subject, it is described in Appendix. There is 
no other theoretical work on current-voltage curves of the sequential two-electron transfer reaction at low concentration of electrolyte, to our knowledge. The current-voltage curve is expressed by Eq. (A17) in the dimensionless form, $f$ (=

$\left.j a / c^{*} F D\right)$ vs. $\zeta_{1}\left(=F\left(E-E_{1}{ }^{\circ}\right) / R T\right)$, with the parameter, $h=F^{2} c^{*} D / R T \kappa=\left(\lambda / \Lambda_{\text {salt }}\right) /\left(c^{*} / c_{\text {salt }}\right)$, where $\kappa$ is the conductivity of electrolyte solution. This parameter were to be the ratio of the conductivity of $\mathrm{A}^{-}$to that of the salt if all the amount of would be reduced to $\mathrm{A}^{-}$. Here, $j$ is the current density, $\lambda$ is the molar ion conductivity of the redox species, $\Lambda_{\text {salt }}$ is that of the salt, and $c_{\text {salt }}$ is concentration of the salt. It is also a function of the standard potential of $E_{1}{ }^{\circ}$ and $E_{2}{ }^{\circ}$ for the first and the second reduction step, respectively.

\subsection{Analysis}

Figure 8 shows current-potential curves for several values of $h$, where the reference potential is taken to be at the solution very close to the electrode, i.e. without $I R$-drop. The voltammogram at $h=0$ ((a) of Fig. 8), corresponding to high concentrations of supporting electrolyte, shows the two sigmoidal waves of which halfwave potentials are at $E_{1}{ }^{\circ}$ and $E_{2}{ }^{\circ}$. The limiting current density of the second wave is twice the first one. When we take $\Lambda_{\mathrm{m}}=0.015 \mathrm{~S} \mathrm{~m}^{2} \mathrm{~mol}^{-1}$ for $\mathrm{KCl}$ [52] and $D=10^{-5} \mathrm{~cm}^{2} \mathrm{~s}^{-1}$, the value of $\lambda / \Lambda_{\mathrm{m}}$ is 0.25 at $25^{\circ} \mathrm{C}$. Since values of $\lambda / \Lambda_{\mathrm{m}}$ do not change largely with kinds of species, the ratio, $c^{*} / c_{\text {salt, }}$ varies mainly $h$. For $h>10$, the first wave shifts to the positive direction because a decrease in the concentration of $\mathrm{A}^{-}$by the electro-repulsive force lets the potential be shifted positively through the Nernst equation. The limiting current density of the first wave is independent of the electric field because of no charge of the reactant, in contrast to charged redox species [12-21]. The second wave has less influence of the potential shift than the first one, especially for $h>10$. The limiting current density of the second wave is $j a / c^{*} D a=-2$, independent of the electric field. This $(f \rightarrow-2)$ can be proved mathematically by taking $E$ to be $-\infty$ in Eq. (A17). Since the second step occurs by diffusion of $\mathrm{A}^{-}$, the limiting current seems to be influenced by 
concentrations of electrolyte [12-21]. Nevertheless, it has to be originated by diffusion of $\mathrm{A}$, and hence the second limiting current is twice the first one.

The above discussion was directed only to the electric field effect but did not include $I R$-drop, because the reference potential was taken to be at the solution near the electrode. Real voltammograms contain the solution resistance, $j a / \kappa$ (see the end of Appendix), and is expressed by Eq. (A22). Figure 9 shows voltammograms including the $I R$-drop for the same values of the parameters in Fig. 8. With an increase in $h$, the waves are drawn out in the direction of the negative potential. Since a degree of the drawn-out wave is approximately linear to the current density, the second wave should be more largely draw out than the first one. The halfwave potentials, $E_{1 / 2}$, of the first wave and the second one were evaluated for various values of $h$, and are plotted, respectively, in Fig. 10(a) and (b) against $c_{\text {salt }} / c^{*}$ at $\lambda / \Lambda_{\text {salt }}=0.25$. The $10 \mathrm{mV}$ shift of the first wave occurs for $c_{\text {salt }} / c^{*}>0.2$, whereas that of the second one does for $c_{\text {salt }} / c^{*}>0.6$.

The experimental halfwave potentials for the first waves of both BQ and TCNQ were not shifted with concentrations of the supporting electrolyte (Fig. 6 and 7). This behavior is in accord with the theoretical variation in Fig. 10(a). We plotted the halfwave potentials of the second wave of BQ and TCNQ against $c_{\text {salt }} / c^{*}$ in Fig. 10. They showed the linear relation with $\log \left(c_{\text {salt }} / c^{*}\right)$, which is different from the theoretical one in Fig. 10(b). The slopes at low concentration domains are $0.18 \pm 0.03 \mathrm{~V}$ and $0.40 \pm 0.05 \mathrm{~V}$ for $\mathrm{BQ}$ and $\mathrm{TCNQ}$, respectively, as shown in the lines in Fig. 10. The values of the slopes are equivalent to the association of 3 and 7 cations ( $\mathrm{TBA}^{+}$) of the electrolyte. In contrast, the slopes at high concentrations are $0.06 \mathrm{~V}$, which corresponds to the association of one cation. Then the second reductions can be regarded as a series of weak association with the cations, as follows

$$
\begin{aligned}
& \mathrm{BQ}^{-}+n \mathrm{TBA}^{+}+\mathrm{e}^{-} \rightarrow \mathrm{BQ}^{2-\cdots}\left(\mathrm{TBA}^{+}\right)_{n} \quad(1<n<3) \\
& \mathrm{TCNQ}^{-}+m \mathrm{TBA}^{+}+\mathrm{e}^{-} \rightarrow \mathrm{TCNQ}^{2-\cdots}\left(\mathrm{TBA}^{+}\right)_{m} \quad(1<m<7)
\end{aligned}
$$

where the mark "‥" means the association of the cations in the ionic atmosphere rather than a stoichiometric species. 
Reactions (3) and (4) can be separated into a chemical (C) reaction and an electron (E) transfer reaction:

$$
\begin{aligned}
& \mathrm{BQ}^{-}+n \mathrm{TBA}^{+} \rightarrow \mathrm{BQ}^{-\cdots}\left(\mathrm{TBA}^{+}\right)_{n} \\
& \mathrm{BQ}^{-\cdots}\left(\mathrm{TBA}^{+}\right)_{n}+\mathrm{e}^{-} \rightarrow \mathrm{BQ}^{2-\cdots}\left(\mathrm{TBA}^{+}\right)_{n} \\
& \mathrm{TCNQ}^{-}+m \mathrm{TBA}^{+} \rightarrow \mathrm{TCNQ}^{-\cdots}\left(\mathrm{TBA}^{+}\right)_{m} \\
& \mathrm{TCNQ}^{-\cdots}\left(\mathrm{TBA}^{+}\right)_{m}+\mathrm{e}^{-} \rightarrow \mathrm{TCNQ}^{2-\cdots}\left(\mathrm{TBA}^{+}\right)_{m}
\end{aligned}
$$

Low concentrations of the electrolyte make the equilibrium in (3C) shift to the left side so that $\left[\mathrm{BQ}^{-}\left(\mathrm{TBA}^{+}\right)_{n}\right]$ becomes low. As a result, the current in (3E) may be smaller than the reduction current of $\mathrm{BQ}+\mathrm{e}^{-} \rightarrow \mathrm{BQ}^{-}$. This prediction calls forth the plot of the currents of the second reduction wave, $I_{\mathrm{L} 2}$, against the concentration of the salt, as is shown in Fig. 11. The currents increase with an increase in the concentration for $c_{\text {salt }}<5$ $\mathrm{mM}$, and then reach the same values as the current at the first reduction currents for $c_{\text {salt }}$ $>30 \mathrm{mM}$. The variation accords qualitatively with the prediction.

We analyze here quantitatively the dependence of $I_{\mathrm{L} 2}$ at $n=1\left(c_{\mathrm{salt}} / c^{*}>3 \mathrm{mM}\right)$ on $c_{\text {salt }}$ for BQ as follows: $I_{\mathrm{L} 2}$ is proportional to $\left[\mathrm{BQ}^{-}\left(\mathrm{TBA}^{+}\right)\right]$, i.e. , $\left[\mathrm{BQ}^{-}\left(\mathrm{TBA}^{+}\right)\right]=k I_{\mathrm{L} 2}$, according to Eq. (3E), for a constant $k$. Then, the equilibrium constant of reaction (3C) is given by

$$
K=\frac{\left[\mathrm{BQ}^{-}\right]\left[\mathrm{TBA}^{+}\right]}{\left[\mathrm{BQ}^{-}\left(\mathrm{TBA}^{+}\right)\right]}=\frac{\left(c^{*}-k I_{\mathrm{L} 2}\right)\left(c_{\text {salt }}-k I_{\mathrm{L} 2}\right)}{k I_{\mathrm{L} 2}}
$$

where $c^{*}$ means concentration of $\mathrm{BQ}$. For high concentrations so that $c_{\mathrm{salt}}>k I_{\mathrm{L} 2}$, Eq. (5) is approximately rewritten as

$$
\frac{c^{*}}{k I_{\mathrm{L} 2}}=\frac{K}{c_{\text {salt }}}+1
$$

Figure 12 shows the inverse plots of $I_{\mathrm{L} 2}$ and $c_{\text {salt }}$, indicating a linear relation in accord with Eq. (6). The variations in Fig. 10 and 12 support the reaction mechanisms (3C)-(4E) of the second waves. The complexes with the cations in reaction (3) and (4) cannot be detected in high concentration of the supporting electrolytes, but are observed at the electrolytes at nanoelectrodes only in low concentrations of supporting 
electrolytes.

The cationic impurity may cause the complexation of Eq. (3C) and (4C). The ionic concentration of impurity estimated from the first reduction wave was $3 \mu \mathrm{M}$ (in Fig. 4) if the ion is $\mathrm{KCl}$. This concentration corresponds to less than $1 \mu \mathrm{M}$ for hydrogen ion by considering the difference in the diffusion coefficients. Voltammograms in Fig. 6 shows that concentrations over $0.5 \mathrm{mM}$ are responsible for the appearance of the second wave. The impurity of $0.001 \mathrm{mM}$ hydrogen ion is too low to participate in the complexation in Eq. (3C) and (4C). Therefore cations involved in the impurity have no effect on the second wave.

We compare our conclusion of the second wave with the reported mechanisms which are the complexation of the dianion with the salt cation [32] and the comproportionation complicated by electrostatic force $[10,11]$. The results reported previously are similar to our result in the context of the participation in the chemical complications. A feature of our strategy is to examine effects of the IR-drop and electrostatic migration by use of the first reduction wave with the help of the theoretical voltammograms. The experimental conditions, especially of impurity of salt concentrations, were controlled by selecting size of microelectrodes and without any reference electrode which would leak salt into the solution. The difference in mechanisms of chemical complications has been revealed under these meticulously controlled conditions.

\section{Conclusions}

When diameters of electrodes are less than $0.4 \mu \mathrm{m}$, steady-state currents of non-charged species can be obtained without addition of salt in dry acetonitrile. Then, BQ and TCNQ exhibit one reduction wave with the one electron transfer, although those in salt solution show two successive waves. Formation of the dianions in the absence of electrolyte requires the overpotential which is larger than the reduction 
potential of acetonitrile. The large overpotential cannot be explained in terms of the electric field effect or solution resistance.

The second reduction wave appears in the electrolyte-added solution, associated with the potential shift. The concentration of the salt does not influence the first reduction waves but varies the second one. The Nernst-Planck equation should cause theoretically the equi-potential shift of both the first wave and the second one. Therefore the influence of the electrolyte concentration only on the second wave can be ascribed to chemical or electrostatic interaction of the redox anion with the salt cation. The ionic association like reactions (3) and (4) can explain the appearance of the second waves.

\section{Appendix}

Our reaction model is a two-step sequential reduction composed of $\mathrm{A}+\mathrm{e}^{-} \leftrightarrow \mathrm{A}^{-}$ and $\mathrm{A}^{-}+\mathrm{e}^{-} \leftrightarrow \mathrm{A}^{2-}$, of which standard potentials are at $E_{1}$ and $E_{2}$, respectively. We use the following five assumptions:

(i) Both reactions obey the Nernst equation;

(ii) The three species have a common value of the diffusion coefficient, $D$;

(iii) The reactions occur at the hemi-spherical electrode $a$ in radius;

(iv) Mass transport is controlled by both diffusion and electric migration; and

(v) Potential distribution in solution obeys the Laplace equation.

The potential distribution should be expressed accurately by the Poisson equation rather than the Laplace equation. Since concentrations of 1:1 electrolyte in our conditions are of the order of $1 \mathrm{mM}$ (Fig. 6 and 7), the Debye length is smaller than $10 \mathrm{~nm}$. This is smaller than the thickness of diffusion layer or diameters of our electrodes. Therefore we can replace the Poisson equation by the Laplace equation.

We denote the fluxes of species $\mathrm{A}, \mathrm{A}^{-}$and $\mathrm{A}^{2-}$ as $J_{0}, J_{1}$ and $J_{2}$, which are caused by diffusion and electric fields. The fluxes are expressed by the Nernst-Planck equation in the angular symmetric spherical coordinate: 


$$
\begin{aligned}
& J_{0}=-D \frac{\partial c_{0}}{\partial r} \\
& J_{1}=-D \frac{\partial c_{1}}{\partial r}+\frac{F}{R T} D c_{1} \frac{\partial \phi}{\partial r} \\
& J_{2}=-D \frac{\partial c_{2}}{\partial r}+\frac{2 F}{R T} D c_{2} \frac{\partial \phi}{\partial r}
\end{aligned}
$$

where $c_{\mathrm{j}}$ is the concentration of $\mathrm{A}^{i-}(i=0,1,2)$, and $\phi$ is the inner potential in the solution phase. The steady-state condition combined with the equation of continuum, $\partial c_{j} / \partial t+\partial\left(r^{2} J_{i}\right) / \partial r=0$, makes $r^{2} J_{i}$ constant, or

$J_{i}=-D k_{i} / r^{2}$

where $k_{i}$ is a constant. On the other hands, a solution of the Laplace equation $\left.\left(r^{-2} \mathrm{~d}\left(r^{2} \mathrm{~d} \phi / \mathrm{d} r\right) / \mathrm{d} r\right)=0\right)$ is given by

$\mathrm{d} \phi / \mathrm{d} r=B r^{-2}$

for a constant, $B$. Inserting Eq. (A4) and (A5) into Eq. (A1)-(A3) yields

$\frac{\mathrm{d} c_{0}}{\mathrm{~d} r}=\frac{k_{0}}{r^{2}}, \frac{\mathrm{d} c_{1}}{\mathrm{~d} r}-\frac{F B}{R T r^{2}} c_{1}=\frac{k_{1}}{r^{2}}, \frac{\mathrm{d} c_{2}}{\mathrm{~d} r}-\frac{2 F B}{R T r^{2}} c_{2}=\frac{k_{2}}{r^{2}}$

Solutions of $c_{\mathrm{i}}$ in Eq. (A6) under conditions, $c_{0} \rightarrow c^{*}, c_{1} \rightarrow 0, c_{2} \rightarrow 0$ for $r \rightarrow \infty$, are given by

$c_{0}=c^{*}-\frac{k_{0}}{r}, c_{i}=\frac{R T k_{i}}{i F B}\left(\exp \left(\frac{-i F B}{R T r}\right)-1\right)($ for $i=1,2)$

The sum of the fluxes of $\mathrm{A}^{i-}$ for $i=0,1,2$ at the electrode $(r=a)$ should be zero because of no adsorption. The sum of Eq. (A4) yields

$k_{0}+k_{1}+k_{2}=0$

The current density is expressed by a sum of $-i F\left(J_{i}\right)_{r=a}$, and hence is given by

$j=-F\left(J_{1}+2 J_{2}\right)_{r=a}=\left(F D / a^{2}\right)\left(k_{1}+2 k_{2}\right)=-\left(F D / a^{2}\right)\left(2 k_{0}+k_{1}\right)$ 
(A9)

where the right hand side was obtained by use of Eq. (A8). On the other hands, the Ohm's law in the solution with the conductivity, $\kappa$, into which Eq. (A5) is inserted is given by

$j=-\kappa(\mathrm{d} \phi / \mathrm{d} r)_{r=a}=-\kappa B a^{-2}$

Eliminating $B$ from Eq. (A7) by use of Eq. (A10), and taking $r$ to be $a$, we have expressions for concentrations at the electrode surface

$$
\left(c_{0}\right)_{r=a}=c^{*}-k_{0} / a,\left(c_{1}\right)_{r=a}=\left(k_{1} / h f a\right)\left(1-\mathrm{e}^{h f}\right),\left(c_{2}\right)_{r=a}=\left(k_{2} / 2 h f a\right)\left(1-\mathrm{e}^{2 h f}\right)
$$

Here, $f$ is the dimensionless current density

$f=j a / c^{*} F D$

and $h$ is the dimensionless parameter, given by

$h=\left(F^{2} c^{*} D / R T \kappa\right)$

$F^{2} D / R T$ means the molar ion conductivity, $\lambda_{1}$, of $1 \mathrm{M} \mathrm{A}_{1}$ [53]. When $\kappa$ is represented by the product of the molar conductivity of salt, $\Lambda_{\text {salt }}$, and concentration of salt, $c_{\text {salt }}$, Eq. (A13) is rewritten as

$$
h=\lambda c^{*} / \Lambda_{\text {salt }} c_{\text {salt }}=\left(\lambda / \Lambda_{\text {salt }}\right)\left(c^{*} / c_{\text {salt }}\right)
$$

Therefore, $h$ stands for the ratio of the conductance of $\mathrm{A}_{1}$ to the salt.

Inserting the surface concentrations (Eq. (A11)) into the Nernst equations for the first and the second reductions, we obtain, respectively

$$
\begin{gathered}
\zeta_{1} \equiv \frac{F\left(E-E_{1}^{\circ}\right)}{R T}=\ln \frac{h f\left(c^{*} a-k_{0}\right)}{k_{1}\left(1-\mathrm{e}^{h f}\right)} \\
\zeta_{2} \equiv \frac{F\left(E-E_{2}^{\circ}\right)}{R T}=\ln \frac{2 k_{1}\left(1-\mathrm{e}^{h f}\right)}{k_{2}\left(1-\mathrm{e}^{2 h f}\right)}
\end{gathered}
$$


Eliminating $k_{2}$ in Eq.(A16) by use of $k_{2}=-k_{0}-k_{1}$ (Eq. (A8)), expressing $k_{1}$ in Eq. (A15) and (A16) as $j$ and $k_{0}$ by use of Eq. (A9), and eliminating $k_{0}$, we obtain via complicated calculation

$$
\frac{h(f+2)}{h+\left(1-\mathrm{e}^{h f}\right) \mathrm{e}^{\zeta_{1}}}=1-\frac{2}{2+\left(1+\mathrm{e}^{h f}\right) \mathrm{e}^{\zeta_{2}}}
$$

Our aim is to obtain current-voltage curves, of which dimensionless form is $f$ vs. $\zeta_{1}$ for parameters of $h$ and $E_{2}-E_{1}$. Since Eq. (A17) is not a closed form of $f$, iterative numerical computations are required. One of them is the Newton-Raphson method. It allowed us to evaluate $f$ for $\zeta_{1}<0$. The other method is iterative computation, which can be made after Eq.(A17) is written as

$$
h f=\left\{1-\frac{2}{2+\left(1+\mathrm{e}^{h f}\right) \mathrm{e}^{\zeta_{2}}}\right\}\left\{h+\left(1-\mathrm{e}^{h f}\right) \mathrm{e}^{\zeta_{1}}\right\}-2 h
$$

A value of the right hand side can be calculated from an initial value $(-0.1)$ of $f$. Thus obtained $h f$ value is again inserted into the right hand side. This process is iterated for $\zeta_{1}$ $>0$ until the values are converged.

We have confirmed that Eq. (A17) tended to the conventional equation for the sequential two electron transfer reaction when $h$ approaches zero

$$
f \rightarrow-\left(\mathrm{e}^{\zeta_{2}}+2\right) /\left(1+\mathrm{e}^{\zeta_{2}}+\mathrm{e}^{\zeta_{1}+\zeta_{2}}\right)
$$

This is identical with the current-voltage curves of multiple electron transfer reactions $[54,55]$.

The electrode potential in Eq. (A17) refers to the potential in the solution very close to the electrode, $\phi_{\mathrm{a}}$. Since the present voltammetry is made in two-electrode cell, the reference potential should be the potential at the far distant counter electrode, $\phi_{\infty}$. Therefore the observed voltage is given by 
$V=E+\phi_{a}-\phi_{\infty}$

Integrating Eq. (A5) yields

$\phi=-B / r+\phi_{\infty}$

By the boundary condition, we have $B=a\left(\phi_{\mathrm{a}}-\phi_{\infty}\right)$, which is equal to $-j a^{2} / \kappa$ from Eq. (A10). Then

$\phi_{a}=\phi_{\infty}-(R T / F) h f$

Eliminating $\phi_{\mathrm{a}}$ from Eq. (A20) and (A21), we have

$V-E_{1}^{o}=E-E_{1}^{o}-(R T / F) h f$

(A22)

The voltage really obtained is the subtraction of $h f$ from $\zeta_{1}$. Eq. (A21) mentions that $(R T / F) h f$ is the solution resistance, which is equal to $j a / \kappa$. 


\section{Figure Captions}

Figure 1. Time-variations of the conductivity of aqueous solutions into which reference electrodes, (open circles) $\mathrm{Ag} \mid \mathrm{AgCl}$, (triangles) $\mathrm{Ag} \mid \mathrm{Ag}_{x} \mathrm{O}$, and (squares) $\mathrm{AgCl}$ coated $\mathrm{Ag}$ wire, were immersed for a few hours during $\mathrm{N}_{2}$ bubbling. The conductivity increased even without immersion of reference electrodes (filled circles).

Figure 2. Voltammograms of $2 \mathrm{mM}$ ferrocene $+2 \mathrm{mM}$ BQ of deaerated acetonitrile without adding electrolyte at $v=0.01 \mathrm{~V} \mathrm{~s}^{-1}$ at microelectrodes with $2 a=$ (a) 0.04 , (b) 0.36 , (c) 0.52 and (d) $1.70 \mu \mathrm{m}$.

Figure 3. Voltammograms in (a) $1.2 \mathrm{mM} \mathrm{BQ}+1 \mathrm{mM}$ ferrocene $+0.1 \mathrm{M} \mathrm{TBAClO}_{4}$ and (b) $0.9 \mathrm{mM}$ TCNQ $+1 \mathrm{mM}$ ferrocene $+0.1 \mathrm{M} \mathrm{TBAClO}_{4}$ of acetonitrile solution at the $1.6 \mathrm{~mm}$ Pt electrode for $v=0.1 \mathrm{~V} \mathrm{~s}^{-1}$.

Figure 4. Plot of $\left(I_{\max }-I_{\min }\right) / a \Delta V$ against $\log (2 a)$ in the solution of $2 \mathrm{mM}$ Ferrocene + (circles) $2 \mathrm{mM} \mathrm{BQ}$ and (triangles) $2 \mathrm{mM}$ TCNQ in acetonitrile when the potential window ranging from -1.2 to $0.6 \mathrm{~V}(\Delta V=1.8 \mathrm{~V})$.

Figure 5. Voltammograms of (a) $2 \mathrm{mM} \mathrm{BQ}+2 \mathrm{mM}$ ferrocene and (b) $2 \mathrm{mM}$ TCNQ +2 $\mathrm{mM}$ ferrocene in acetonitrile without adding electrolyte at $2 a=40 \mathrm{~nm}$ electrode for $v=$ $10 \mathrm{mV} \mathrm{s}^{-1}$.

Figure 6. Voltammograms of $2 \mathrm{mM}$ TCNQ $+2 \mathrm{mM}$ ferrocene in acetonitrile including (a) 0, (b) 0.5, (c) 1, (d) 2, (e) 5, (f) 10, (g) 30 and (h) $60 \mathrm{mM} \mathrm{TBAClO}_{4}$ at $2 a=120 \mathrm{~nm}$ electrode for $v=20 \mathrm{mV} \mathrm{s}^{-1}$. 
Figure 7. Voltammograms of $2 \mathrm{mM} \mathrm{BQ}+2 \mathrm{mM}$ ferrocene in acetonitrile including (a) 0 , (b) 0.5 , (c) 2 , (d) 10 , (e) 30 and (f) $100 \mathrm{mM} \mathrm{TBAClO}_{4}$ at $2 a=180 \mathrm{~nm}$ electrode for $v=$ $20 \mathrm{mV} \mathrm{s}^{-1}$.

Figure 8. Electric migrational components of voltammograms calculated from Eq. (A17) for $\lambda / \Lambda_{\mathrm{m}}=0.25$ at $c_{\text {salt }} / c^{*}=$ (a) 100 , (b) 0.33 , (c) 0.1 , (d) 0.025 and (e) 0.0125 .

Figure 9. Voltammograms including both the electric migration and the $I R$-drop calculated from Eq. (A22) for $\lambda / \Lambda_{\mathrm{m}}=0.25$ at $c_{\text {salt }} / c^{*}=$ (a) 100 , (b) 0.33 , (c) 0.1 , (d) 0.025 and (e) 0.0125 .

Figure 10. Variations of the theoretical halfwave potentials of (a) the first and (b) the second waves calculated from Eq. (A17) with $\log \left(c_{\text {salt }} / c^{*}\right)$, where potential values were intentionally shifted by (a) $-0.5 \mathrm{~V}$ and (b) $-1.5 \mathrm{~V}$ in order to avoid graphical overlap. Experimental halfwave potentials for the second wave of (triangles) $2 \mathrm{mM} \mathrm{BQ}$ and (circles) $2 \mathrm{mM}$ TCNQ are plotted against $\log \left(c_{\text {salt }} / c^{*}\right)$. The two kinds of lines were drawn for low and high concentrations of the salt.

Figure 11. Plot of the currents of the second reduction wave of (triangles) BQ and (circles) TCNQ against $c_{\text {salt }}$ under the same conditions as in Fig. 10.

Figure 12. Variation of the inverse current with the inverse concentration of the salt under the same conditions as in Fig. 10. 
Fig. 1
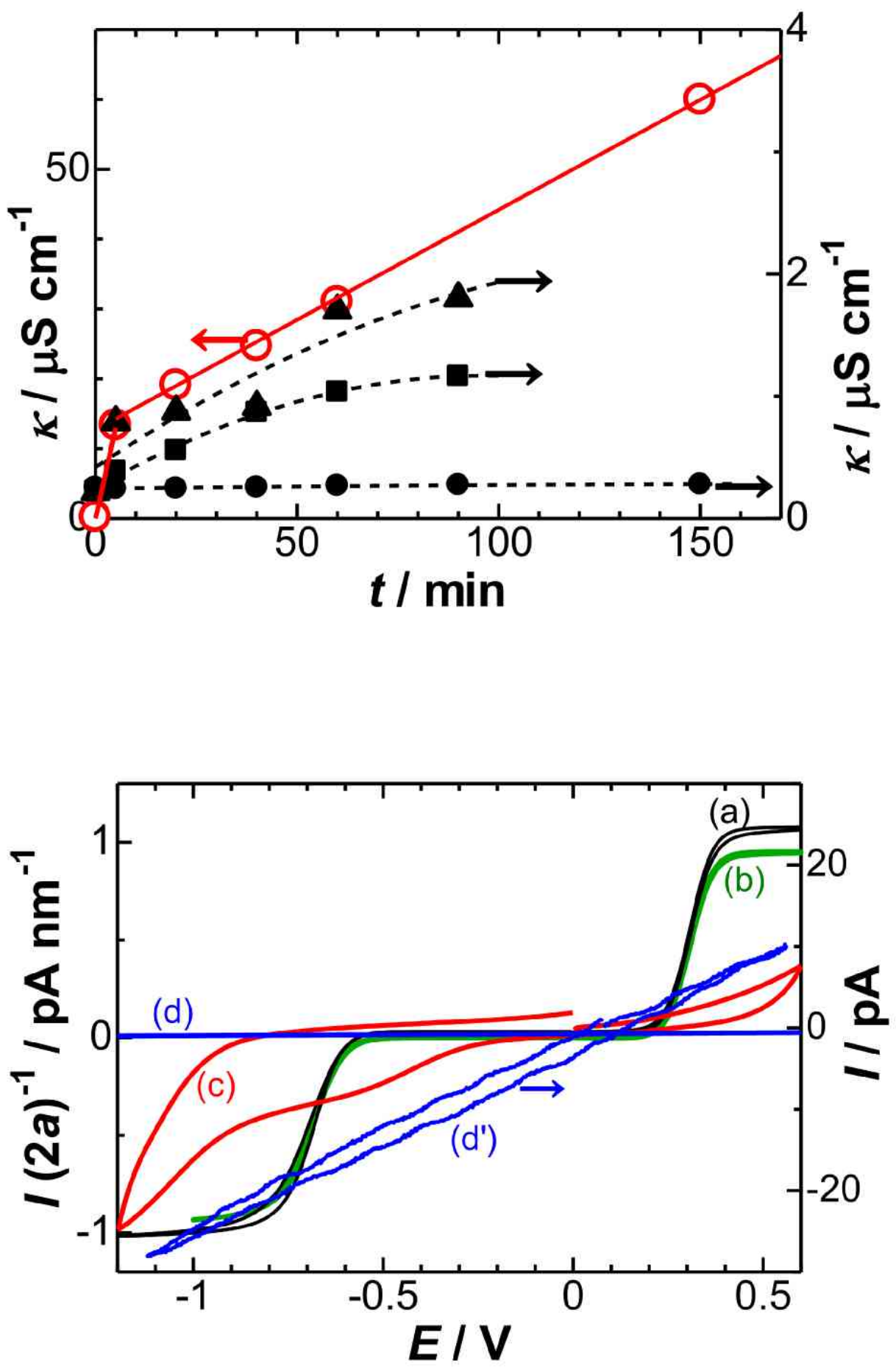

Fig. 2 

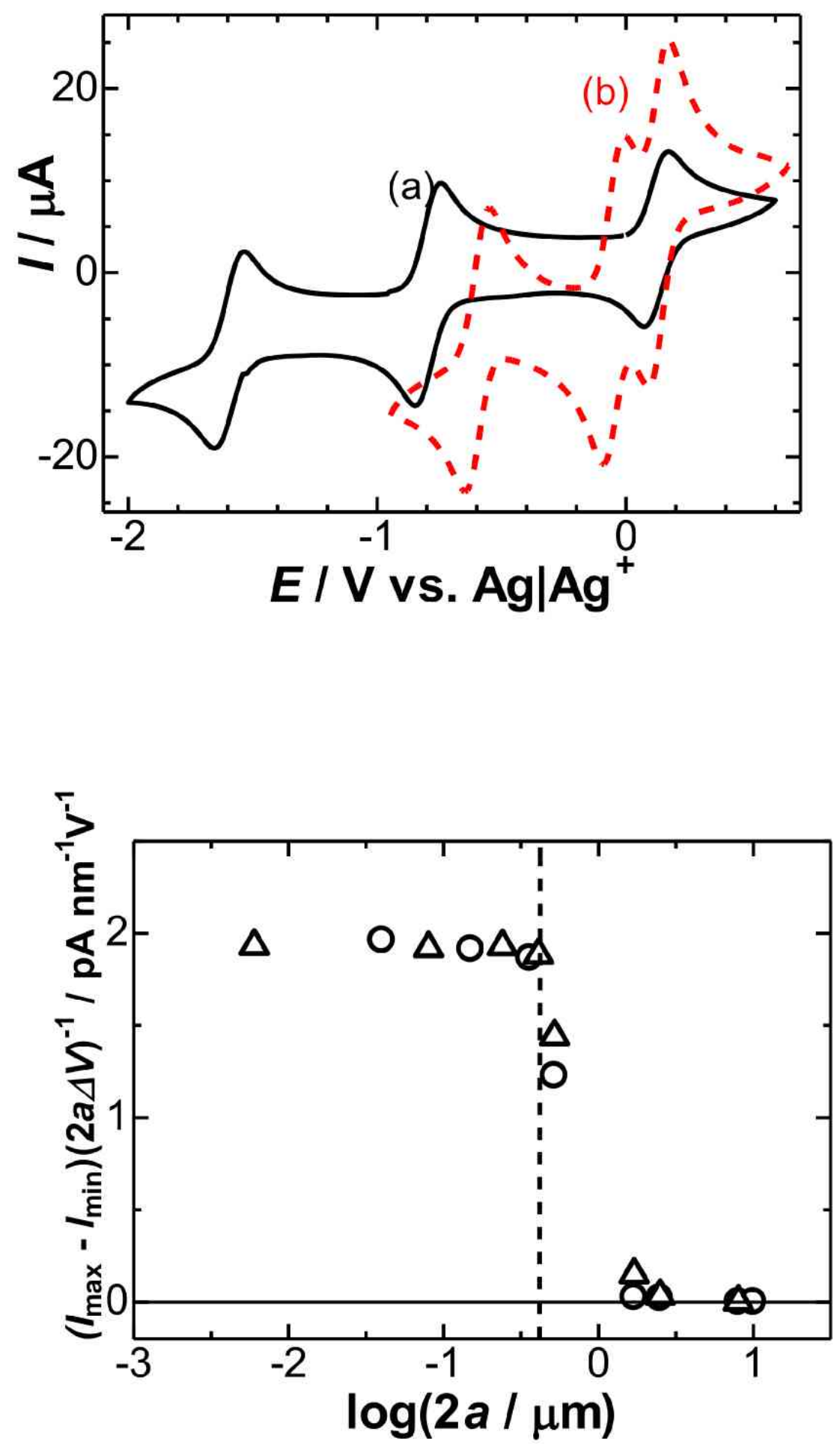

Fig. 4 


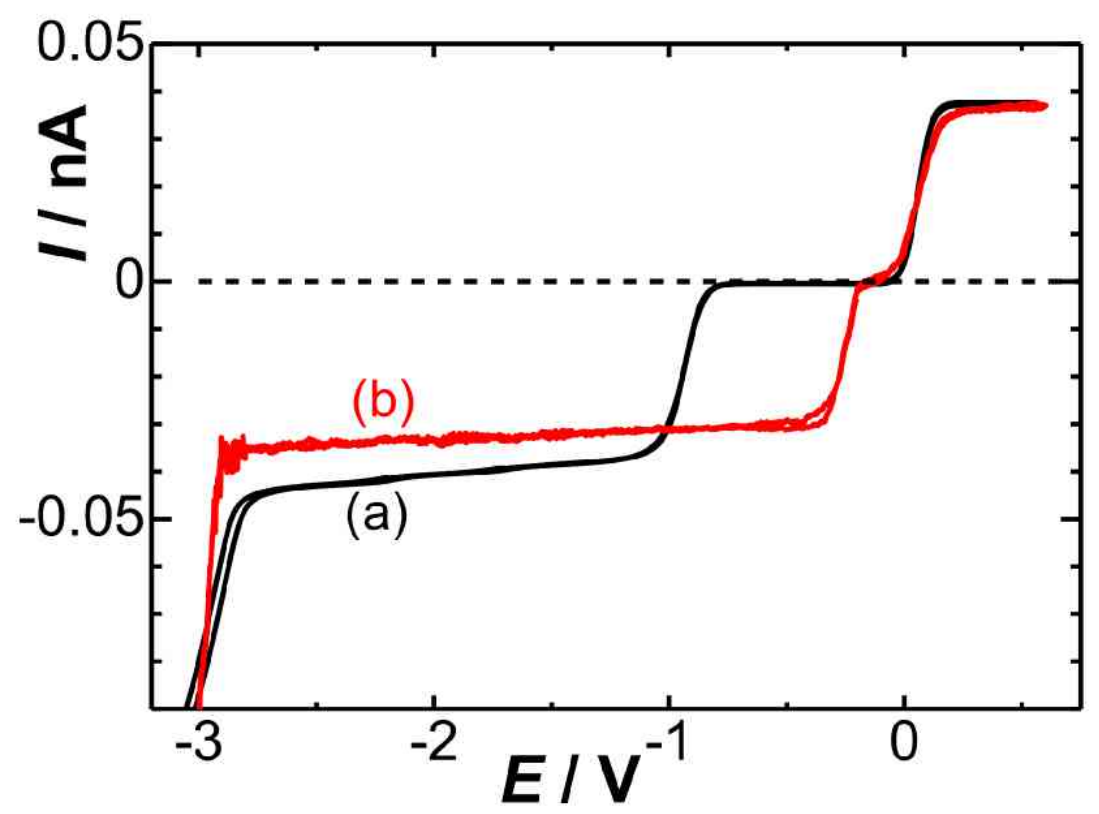

Fig. 5

Fig. 6

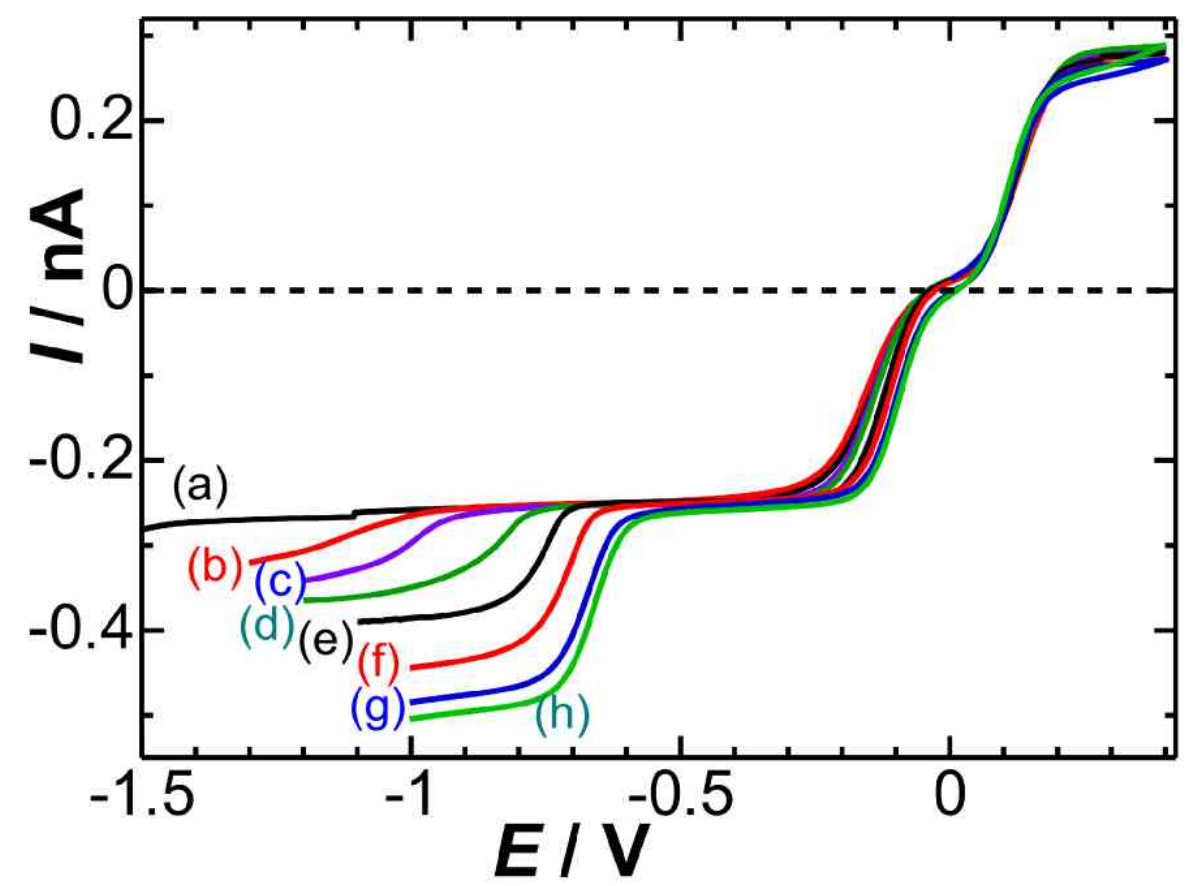




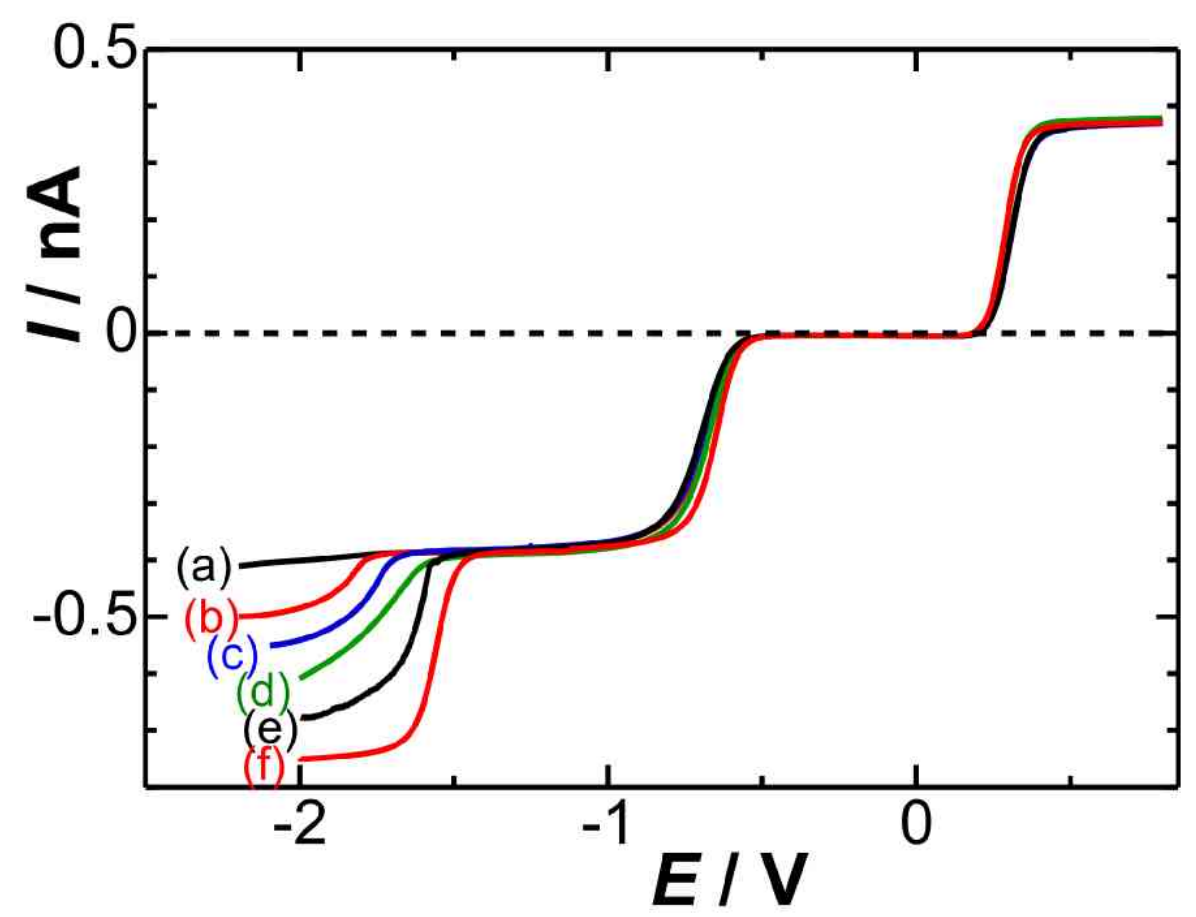

Fig. 7

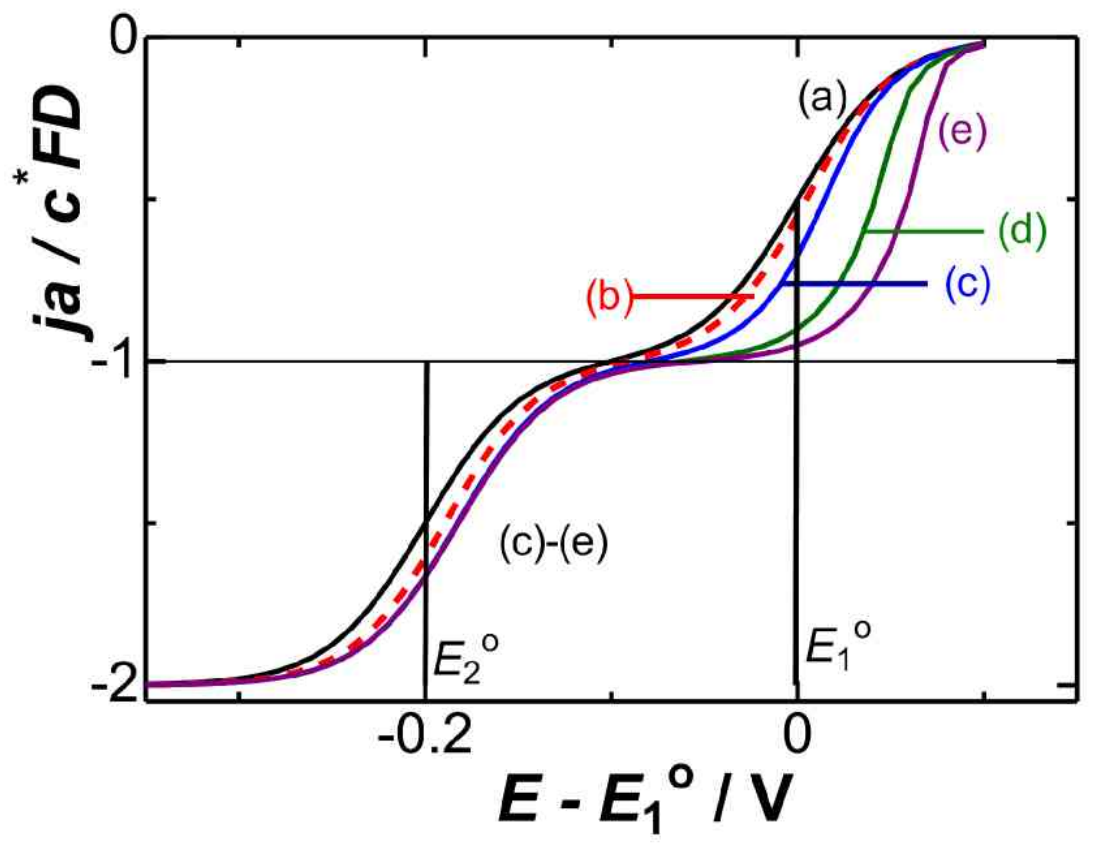

Fig. 8 


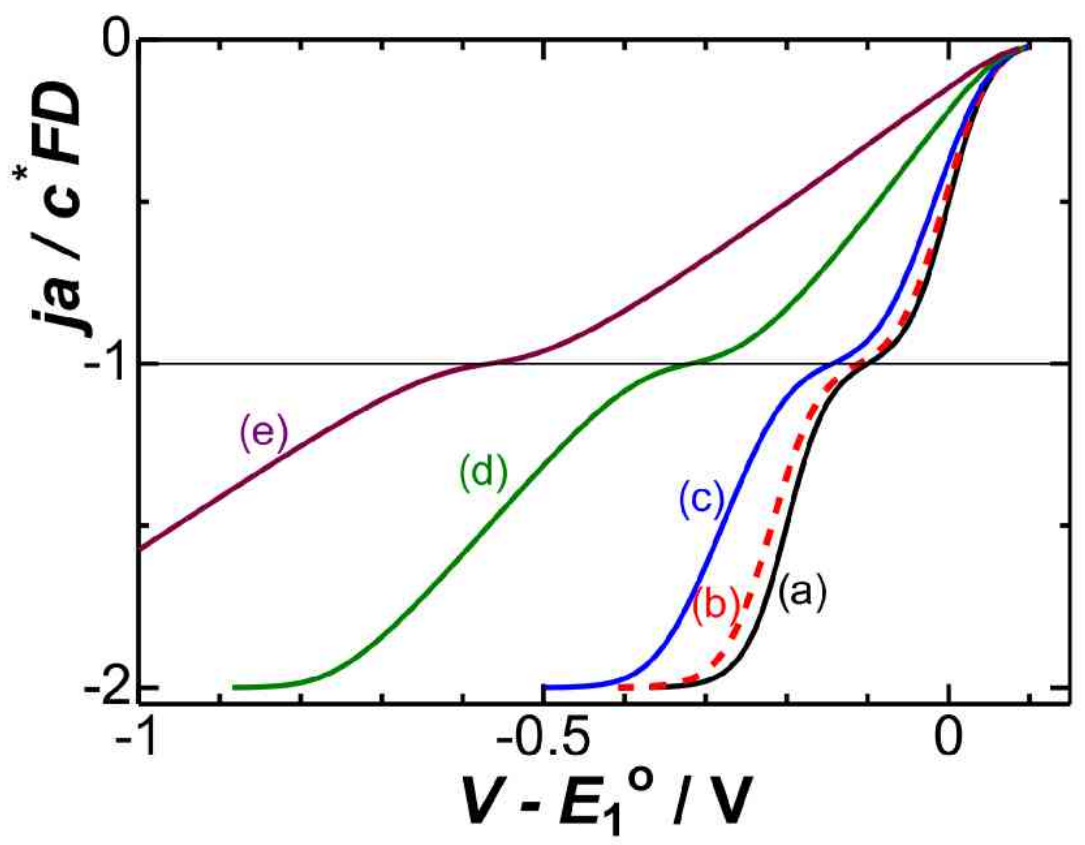

Fig. 9

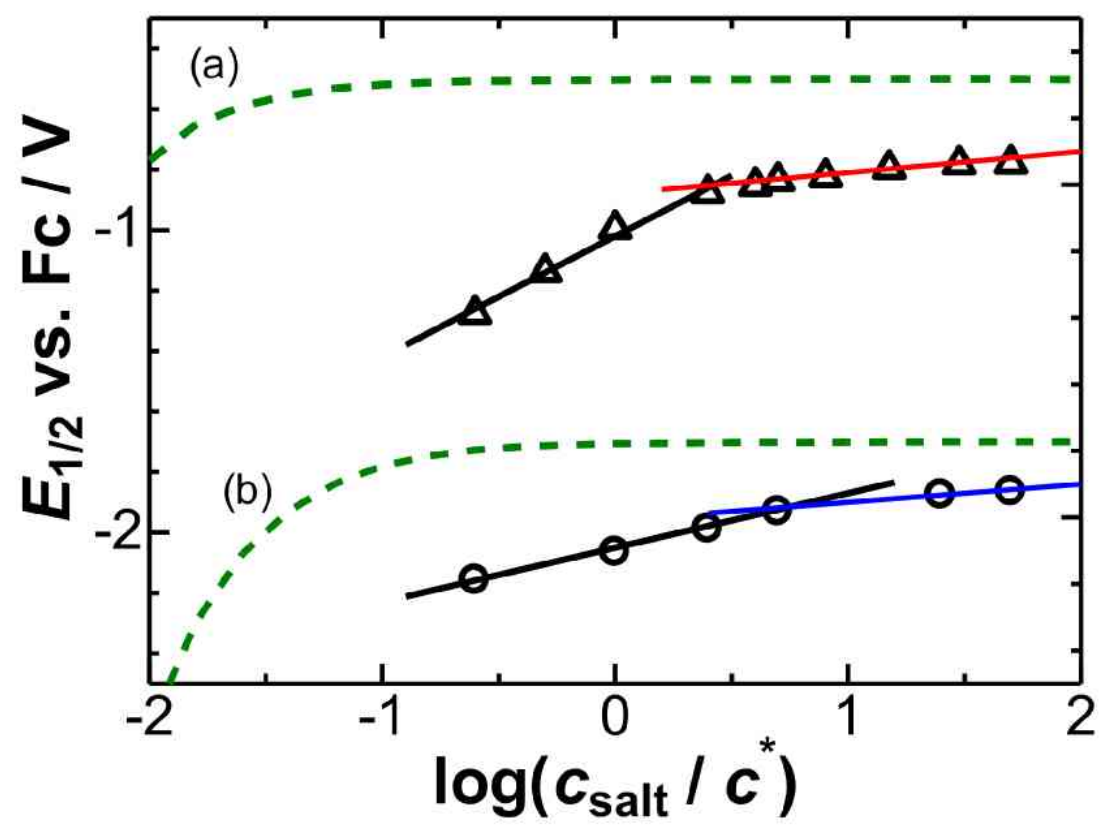

Fig. 10 
Fig. 11

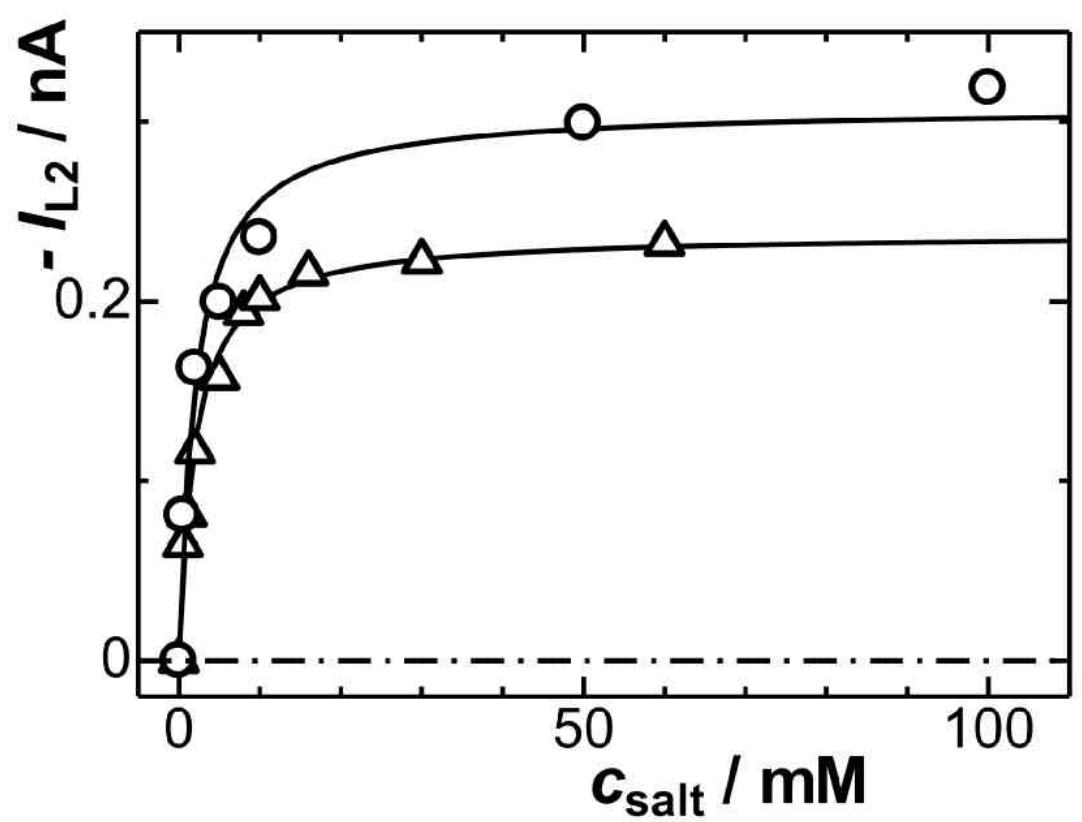

Fig. 12

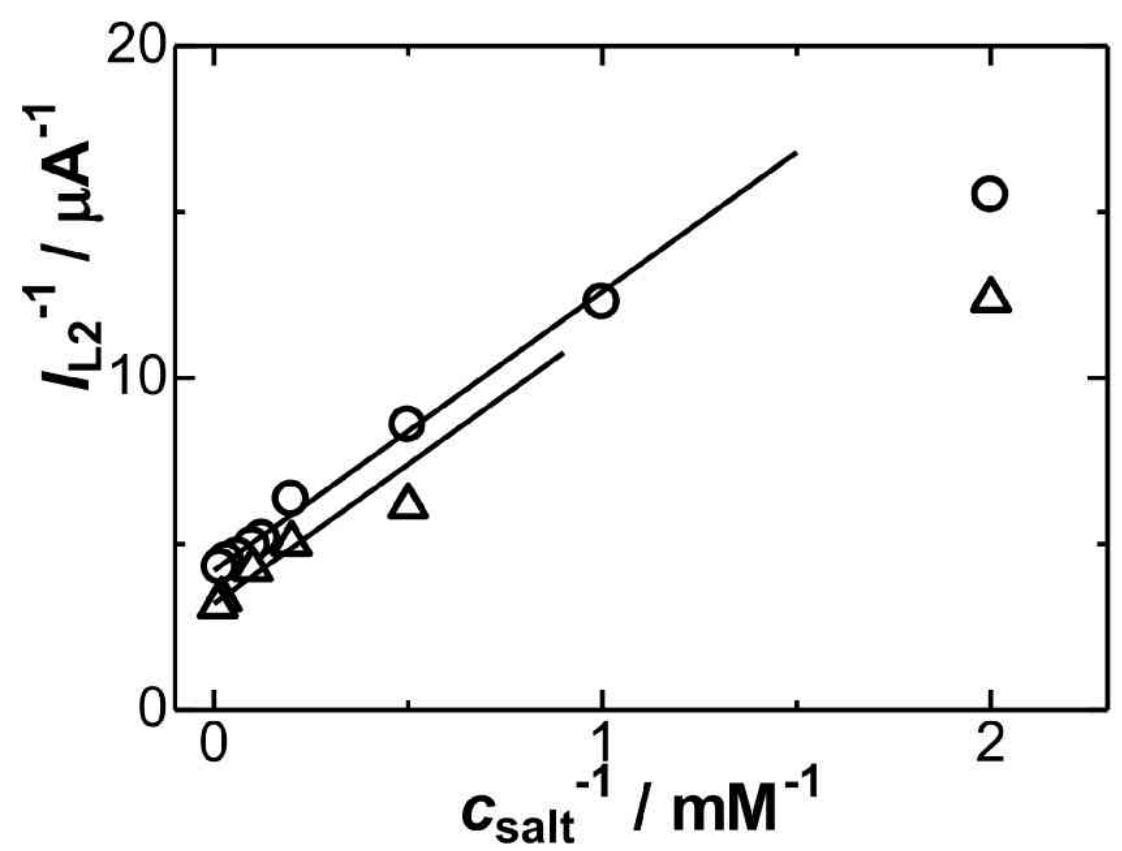




\section{References}

[1] I. Slendyk, Coll. Czech. Chem. Comm. 3 (1931) 385.

[2] J.J. Lingane, I.M. Kolthoff, J. Am. Chem.Soc. 61 (1939) 1045-1051.

[3] J. Heyrovský, J Kůta, Principles of Polarography, Academic Press, New York, Chapter 5, 1966, pp.65-72.

[4] M.J. Peña, M. Fleischmann, N. Garrard, J. Electroanal. Chem. 220 (1987) 31-40.

[5] M. Ciszkowska, J.G. Osteryoung, Anal. Chem. 67 (1995) 1125-1131.

[6] A.M. Bond, P.A. Lay, J. Electroanal. Chem. 199 (1986) 285-295.

[7] J. Cassidy, S. B. Khoo, S. Pons, M. Fleischmann, J. Phys. Chem. 89 (1985) 3933-3935.

[8] T. Dibble, S. Bandyopadhyay, J. Ghoroghchian, J.J. Smith, F. Sarfarazi, M. Fleischmann, S. Pons, J. Phys. Chem. 90 (1986) 5275-5277.

[9] J.O. Howell, R. M. Wightman, Anal. Chem. 56 (1984) 524-529.

[10] J.D. Norton, W.E. Benson, H.S. White, Anal. Chem. 63 (1991) 1909-1914.

[11] J.D. Norton, H.S. White, J. Electroanal. Chem. 325 (1992) 341-350.

[12] C. Amatore, M.R. Deakin, R.M. Wightman, J. Electroanal. Chem. 225 (1987) 49-63.

[13] C. Amatore, B. Fosset, J. Bartelt, M.R. Deakin, R.M. Wightman, J. Electroanal. Chem. 256 (1988) 255-268.

[14] J.B. Cooper, A.M. Bond, K.B. Oldham, J. Electroanal. Chem. 331 (1992) 877-895.

[15] K.B. Oldham, J. Electroanal. Chem. 250 (1988) 1-21.

[16] B. D. Pendley, H. D. Abruna, J. D. Norton, W. E. Benson, H. S. White, Anal. Chem. 63 (1991) 2766-2771.

[17] K.B. Oldham, J. Electroanal. Chem. 337 (1992) 91-126.

[18] K. Aoki, J. Electroanal. Chem., 488, (2000) 25-31.

[19] J. G. Limon-Petersen, E.J.F. Dickinson, S. R. Belding, N.V. Rees, R.G. Compton, J. Electroanal. Chem. 650 (2010) 135-142. 
[20] S.R. Belding, R. G. Compton, J. Electroanal. Chem. 683 (2012) 1-13.

[21] W. Hyk, Z. Stojek, Anal. Chem. 74 (2002) 4805-4813.

[22] M. Ciszkowska, Z. Stojek, J. Electroanal. Chem. 466 (1999) 129-143.

[23] M. Ciszkowska, Z. Stojek, Anal. Chem. 72 (2000) 754A-760A.

[24] D.J. Griffiths, Introduction to Electrodynamics, Second ed. Prentice Hall, New Jersey, 1989, p. 85.

[25] A.J. Bard, L.R. Faulkner, Electrochemical Methods; Fundamentals and Applications, Second edition, Wiley, 2001, pp. 28-29.

[26] S. Daniele, C. Bragato, M.A. Baldo, J. Electroanal. Chem. 439 (1997) 153-161.

[27] S. Daniele, C. Bragato, M.A. Baldo, J. Electroanal. Chem. 456 (1998) 105-112

[28] M. Palys, Z. Stojek, M. Bos, W. van der Linden, Anal. Chim. Acta 337 (1997) $5-28$.

[29] M. Palys, E. Rostek, Z. Stojek, Anal. Chim. Acta 377 (1998) 29-37.

[30] A. Jaworski, Z. Stojek, J.G. Osteryoung, J. Electroanal. Chem. 558 (2003) 141-153.

[31] M. W. Lehmann, D. H. Evans, Anal. Chem. 71 (1999) 1947-1950.

[32] G.N. Kamau, J.F. Rusling, J. Elecrroanal. Chem. 292 (1990) 187-198.

[33] C. Amatore, S. C. Paulson, H. S. White, J. Electroanal. Chem. 439 (1997) 173-182.

[34] J.B. Cooper, A.M. Bond, Anal. Chem. 65 (1993) 2724-2730.

[35] D. Suwatchara, N.V. Rees, R.G. Compton, J. Electroanal. Chem. 669 (2012) 14-20.

[36] K. Miyoshi, M. Oyama, S. Okazaki, Electroanalysis 13 (2001) 917-922.

[37] M. Oyama, R.D. Webster, M. Suarez, F. Marken, R.G. Compton, S. Okazaki, J. Phys. Chem. B 102 (1998) 6588-6595.

[38] Y. Wang, E.I. Rogers, S.R. Belding, R.G. Compton, J. Electroanal. Chem. 648 (2010) 134-142.

[39] Z. Rongfeng, D.H. Evans, J. Electroanal. Chem. 385 (1995) 201-207.

[40] W. Hyk, Z. Stojek, J. Electroanal. Chem. 439 (1997) 81-88.

[41] A. Jaworski, M. Donten, Z. Stojek, Anal. Chim. Acta, 305 (1995) 106-113. 
[42] C. Li, K.J. Aoki, T. Nishiumi, J. Chen, Report Electrochem. in press.

[43] W. Hyk, Z. Stojek J. Electroanal. Chem. 422 (1997) 179-184.

[44] X. Gao, H.S. White, Anal. Chem. 67 (1995) 4057-4064.

[45] K.B. Oldham, T.J. Cardwell, J.H. Santos, A.M. Bond, J. Electroanal. Chem. 430 (1997) 39-46.

[46] K. Aoki, C. Zhang, J. Chen, T. Nishiumi, Electrochim. Acta 55 (2010) 7328-7333.

[47] K. Aoki, H. Takeuchi, J. Chen, T. Nishiumi, Review of Polarography, 57 (2011) 101-119.

[48] K. Aoki, J. Chen, H. Zhang, J. Electroanal. Chem. 610 (2007) 211-217.

[49] M.W. Lehmann, D.H. Evans, J. Electroanal. Chem. 500 (2001) 12-20

[50] M. Oyama, F. Marken, R. D. Webster, J. A. Cooper, R. G. Compton, S. Okazaki, J. Electroanal. Chem. 451 (1998) 193-201.

[51] J.S. Newman, Electrochemical Systems, Prentice-Hall Inc. Englewood Cliffs,1973, p. 344 .

[52] P. W. Atkins, Physical Chemistry, Sixth edition, Oxford University Press, Oxford, 1998, p. 738.

[53] P.W. Atkins, Physical Chemistry, Sixth Edition, Oxford University Press, pp. 740-750.

[54] I. Ruzic, J. Electroanal. Chem. 52 (1974) 331-354.

[55] K. Aoki, J. Chen, J. Electroanal. Chem. 380 (1995) 35-45. 